\title{
SUSCETIBILIDADE DA VEGETAÇÃO AO FOGO NO SUL DO AMAZONAS SOB CONDIÇÕES METEOROLÓGICAS ATÍPICAS DURANTE A SECA DE 2005
}

\author{
SUMAIA SALDANHA DE VASCONCELOS ${ }^{1}$,PHILIP MARTIN FEARNSIDE ${ }^{1}$, PAULO MAURÍCIO \\ LIMA DE ALENCASTRO GRAÇA ${ }^{1}$, PAULO RICARDO TEIXEIRA DA SILVA ${ }^{2}$, \\ DAVID VALENTIM DIAS ${ }^{1}$
}

\author{
${ }^{1}$ Instituto Nacional de Pesquisas da Amazônia, Coordenação de Dinâmica Ambiental, Manaus, AM, Brasil \\ ${ }^{2}$ Universidade do Estado do Amazonas, Manaus, AM, Brasil
}

sumaia.vasconcelos@inpa.gov.br,pmfearn@inpa.gov.br,pmlag@inpa.gov.br, paulo.ricardo.teixeira@gmail.com,david.valentim@bol.com.br

Recebido Maio de 2014 - Aceito Agosto de 2014

\begin{abstract}
RESUMO
As condições meteorológicas desempenham importante função no comportamento de queimadas e incêndios florestais na Amazônia. Em anos de secas severas, as queimadas utilizadas no manejo da terra podem sair do controle e queimar extensas áreas de vegetação. Parâmetros meteorológicos e focos de calor foram utilizados para avaliar a suscetibilidade da vegetação ao fogo no sul do Amazonas em um ano sem seca (2004) e com seca severa (2005). O número de células suscetíveis ao fogo foi 84\% maior em 2005 (72\%), comparando com 2004 (39\%). Em 2005, o número de células com focos aumentou $66 \%$ e o número de focos $121 \%$. Em 2004, $65 \%$ dos focos ocorreram com precipitação entre 40 e $90 \mathrm{~mm}, 96 \%$, com temperatura média entre 26 e $28^{\circ} \mathrm{C}$, e $89 \%$ com umidade inferior a $65 \%$. Em 2005, 83\% dos focos ocorreram com precipitação inferior a $70 \mathrm{~mm}, 96 \%$ com temperatura média entre 24 e $28{ }^{\circ} \mathrm{C}$ e $99 \%$ com umidade inferior a $65 \%$. Os parâmetros meteorológicos apresentaram tendência de separação entre anos, mas não entre áreas com e sem focos $(\mathrm{PC} 1=84 \%)$. Houve maior amplitude de variação desses parâmetros no ano com seca severa, proporcionando um tempo mais quente e seco, potencializando a suscetibilidade da vegetação ao fogo.
\end{abstract}

Palavras-chave: focos de calor; queimadas; flamabilidade; parâmetros meteorológicos; Amazônia.

\begin{abstract}
VEGETATION SUSCEPTIBILITY to FIRE IN the SOUTHERN AMAZONAS UNDER ATYPICAL WEATHER CONDITIONS DURING THE 2005 DROUGHT

Weather conditions play an important role in the behavior of fires both in agricultural and pasture management and in forest wildfires in Amazonia. In severe drought years, the fires used for the management of land can escape from human control and burn large areas of vegetation. Meteorological parameters and hotspot locations were used to evaluate the susceptibility of the vegetation to fire in the southern portion of the state of Amazonas in a year without drought (2004) and a year with severe drought (2005). The number of cells susceptible to fire was $84 \%$ higher in $2005(72 \%)$ compared with $2004(39 \%)$. In 2005, the number of cells with hotspots increased by $66 \%$ and the number of hotspots by $121 \%$. In $2004,65 \%$ of the hotspots occurred in locations with 40 and $90 \mathrm{~mm}$ precipitation, $96 \%$ with an average temperature of 26 to $28{ }^{\circ} \mathrm{C}$, and $89 \%$ with less than $65 \%$ humidity. In $2005,83 \%$ of the hotspots occurred when rainfall was less than $70 \mathrm{~mm}, 96 \%$ with average temperature between 24 and $28{ }^{\circ} \mathrm{C}$ and $99 \%$ with air humidity below $65 \%$. The meteorological parameters differed between years but not between areas with and without hotspots $(\mathrm{PC} 1=84 \%)$. There was a higher amplitude variation in these meteorological parameters in the severe drought year, providing hotter and drier weather, thus increasing the susceptibility of vegetation to fire.
\end{abstract}

Keywords: hotspots; fire; flammability; meteorological parameters; Amazon. 


\section{INTRODUÇÃO}

Na Amazônia, durante a estação seca, a queima de pastagens, cultivos agrícolas, vegetação secundária e a prática de corte-e-queima da floresta são muito comuns no manejo da terra (Fearnside, 1990; Nepstad et al., 1999; Carvalho Jr. e Lacava, 2003). No entanto, em anos de seca de grande magnitude e persistência, o risco de incêndios aumenta consideravelmente (Cochrane, 2003; Nepstad et al., 2004; Alencar et al., 2011), pois as queimadas têm a atividade humana como principal fonte de ignição (Cardoso et al., 2003; Chuvieco et al., 2008; Morton et al., 2008), podendo sair do controle e afetar extensas áreas de florestas (Barbosa e Fearnside, 1999; Brown et al., 2006; Asner e Alencar, 2010; Vasconcelos et al., 2013a; Brando et al., 2014).

As condições meteorológicas desempenham importante papel no comportamento de queimadas e incêndios florestais. A precipitação aumenta o teor de umidade do material combustível, diminuindo a possibilidade de incêndios na vegetação (Uhl e Kauffman, 1990; Trollope et al., 2004). Por outro lado, a falta de chuva durante uma seca prolongada, além de diminuir o teor de umidade do material combustível, aumenta a queda das folhas em consequência do estresse hídrico (Nepstad et al., 1999) acrescentando maior quantidade de material combustível e tornando-o suscetível ao fogo (Nepstad et al., 2007).

Florestas do leste da bacia Amazônica tornaram-se inflamáveis durante a seca de 1992, quando choveu apenas $95 \mathrm{~mm}$ em 5,5 meses (Nepstad et al., 1994). No Estado do Amazonas, mais de $95 \%$ dos focos de calor ocorrem nos meses de menor precipitação (inferior a $100 \mathrm{~mm} / \mathrm{mês}$ ) e o número de eventos de fogo aumenta à medida que a precipitação diminui (Vasconcelos et al., 2013b).

A umidade do ar afeta diretamente o teor de umidade do material combustível (Uhl e Kauffman, 1990) e tem estreita relação com sua flamabilidade (Nepstad et al., 2004; Ray et al., 2005). Fogos experimentais conduzidos no Estado do Pará mostraram que a combustão em diferentes tipos de cobertura vegetal ocorreu com umidade do ar entre 35\% e 97\% (Uhl e Kauffman, 1990; Ray et al., 2005), e a propagação do fogo em floresta intacta no Estado do Acre ocorreu com umidade do ar inferior a 64\% (Mendoza, 2003).

A temperatura do ar também propicia condições de tempo seco favoráveis à ocorrência de queimadas e incêndios, cujo principal efeito em relação à suscetibilidade ao fogo é o de reduzir o teor de umidade do material combustível (Trollope et $a l ., 2004)$, pois quanto maior a temperatura do ar, mais provável uma fonte de ignição resultar em queimada (Pereira Jr., 2003). Estudos de micrometeorologia na Amazônia mostram que o fogo pode ocorrer com temperatura do ar acima de $24^{\circ} \mathrm{C}$, dependendo do tipo de cobertura vegetal (Ray et al., 2005) e a temperatura acima de $29^{\circ} \mathrm{C}$ proporciona condição favorável à propagação do fogo na floresta (Mendoza, 2003).

Diante deste contexto, informações sobre as condições meteorológicas propícias à ocorrência de queimadas e incêndios florestais na Amazônia, e a grande influência que possuem na flamabilidade e suscetibilidade da vegetação ao fogo são relevantes. Este trabalho teve como objetivo determinar, utilizando dados de imagens de satélites, as condições meteorológicas, nas quais ocorreu o maior número de focos de calor na vegetação do sul do Amazonas em um ano sem (2004) e com (2005) seca severa.

\section{MATERIAL E MÉTODOS}

\section{1 Área de estudo}

A área de estudo localiza-se na porção sul do Estado do Amazonas compreendendo os municípios de Boca do Acre, Lábrea, Canutama, Humaitá, Manicoré, Novo Aripuanã e Apuí, e abrange uma área de $296.500 \mathrm{~km}^{2}$, correspondendo a $20 \%$ da área total do Estado (IBGE, 2012) entre as latitudes $4^{\circ} 26^{\prime} \mathrm{S}$ e $9^{\circ} 39^{\prime} \mathrm{S}$ e os paralelos 58 $4^{\prime} \mathrm{O}$ e $69^{\circ} 21^{\prime} \mathrm{O}$ (Figura 1). Nessa área, cerca de $4.310 \mathrm{~km}^{2}$ são pastagens e $622 \mathrm{~km}^{2}$ são destinados à agricultura (IBGE, 2012); o desmatamento acumulado até 2012 foi de $11.583,5 \mathrm{~km}^{2}$ (INPE, 2014) e foram detectados anualmente cerca de $50 \%$ dos focos de calor registrados no Amazonas (Vasconcelos et al., 2013b).

Os tipos de vegetação predominantes são Floresta ombrófila densa, Floresta ombrófila aberta e Savana (IBGE, 2004). O clima predominante nessa região é tropical quente e úmido (IBGE, 2002) do tipo Am, na maior parte do sul do Amazonas, conforme classificação climática de Köppen (Alvares et al., 2013). A precipitação anual média varia entre $2.200 \mathrm{~mm}$ no extremo sudoeste e $3.100 \mathrm{~mm}$ no sudeste (Alvares et al., 2013), com 1 a 4 meses de seca com precipitação menor que $100 \mathrm{~mm}$ (Sombroek, 2001). A temperatura média anual varia entre $24^{\circ}$ e $26^{\circ} \mathrm{C}$ (Alvares et al., 2013), com frequentes ondas de frio (friagens) ao longo do eixo sul com duração de 3 a 8 dias e temperatura média no mês mais frio superior a 18 ${ }^{\circ} \mathrm{C}$. A umidade relativa do ar é bastante elevada variando entre 85\% e 90\% (RadamBrasil, 1983).

\subsection{Dados meteorológicos}

Em estudos de suscetibilidade da vegetação ao fogo são comumente utilizadas variáveis meteorológicas em escala temporal diária, tais como: precipitação, temperatura do ar, umidade relativa do ar, velocidade e direção do vento, número de dias sem chuva (Trollope et al., 2004). Além dessas variáveis, 


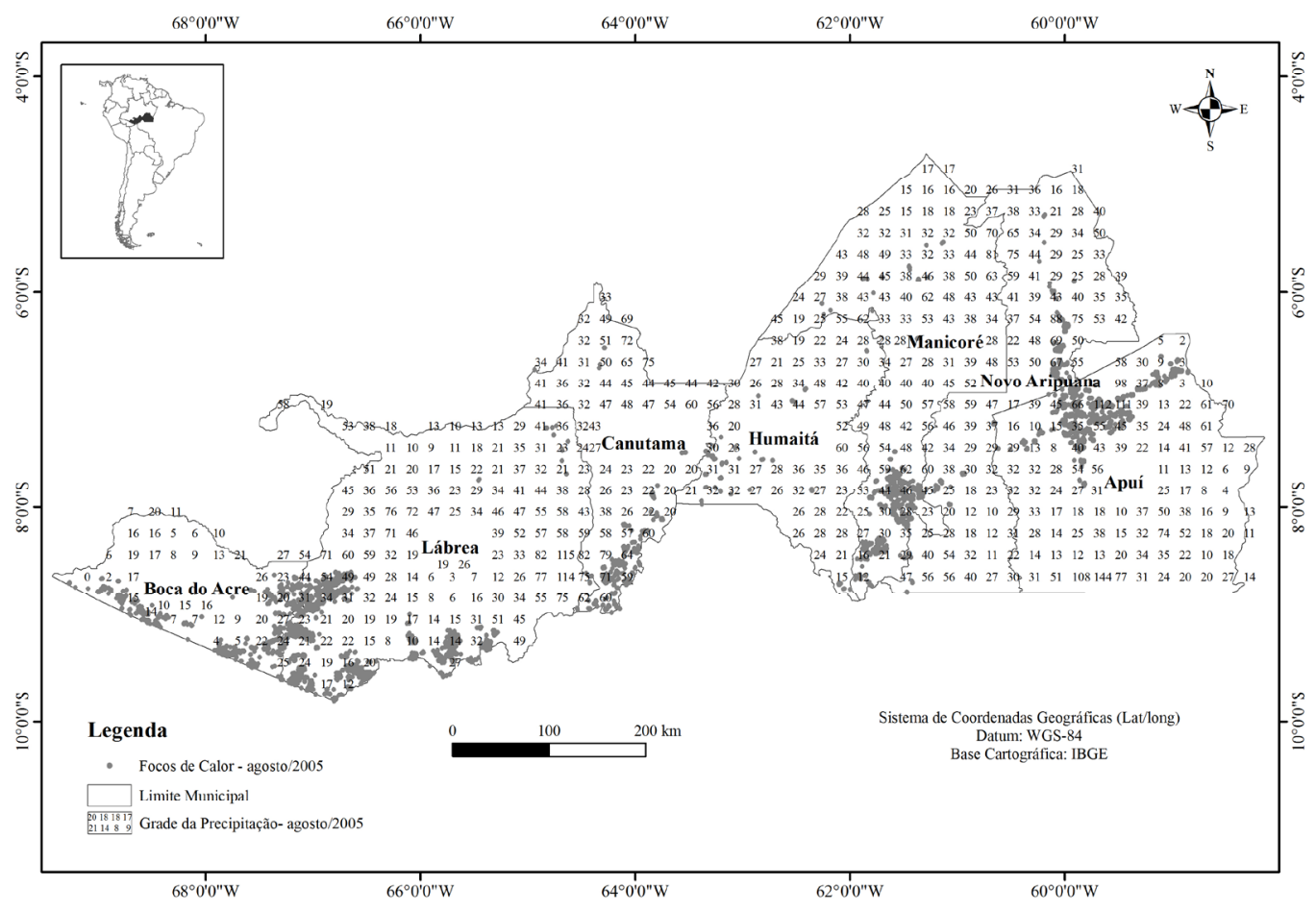

Figura 1 - Área de estudo no sul do Amazonas com extensão de 296.789 km² apresentando os limites dos municípios de Boca do Acre, Lábrea, Canutama, Humaitá, Manicoré, Novo Aripuanã e Apuí, distribuição espacial de focos de calor e a grade numérica da precipitação (mm) de agosto de 2005.

componentes ambientais, econômicos e de infraestrutura também são relevantes, principalmente para fins de modelagem. Tendo em vista as grandes dificuldades encontradas na aquisição e disponibilização dos dados e a magnitude da extensão da área de estudo, neste trabalho foram utilizados somente os seguintes parâmetros meteorológicos mensais: precipitação, temperatura do ar (máxima, média e mínima) e umidade relativa do ar dos meses de julho, agosto, setembro e outubro de 2004 (sem seca severa) e de 2005 (com seca severa).

A precipitação acumulada mensal foi obtida do produto MERGE fornecido pelo Instituto Nacional de Pesquisas Espaciais (INPE), que é a combinação dos dados de precipitação observados em estações que são reportadas com regularidade pelo Global Telecommunication System (GTS), plataformas de coletas de dados (PCDs) e centros regionais do Brasil com os dados de precipitação estimados pelo algoritmo 3B42RT do satélite Tropical Rainfall Measuring Mission (TRMM). Os dados de temperatura do ar e umidade relativa do ar foram oriundos das plataformas de coletas de dados (PCDs) e centros regionais do Brasil disponibilizados pelo Centro de Previsão do Tempo e Estudos Climáticos (CPTEC/INPE).

Se comparado com as regiões nordeste, sudeste e sul a densidade das estações meteorológicas da região do estudo é muito baixa (Alvares et al., 2013), com uma estação a cada $15.500 \mathrm{~km}^{2}$, com distribuição irregular e insuficiente para toda a área do estudo e com sua totalidade localizada nas sedes administrativas de cada município.

Um fator limitante associado às medidas meteorológicas é a baixa densidade de pontos de coleta, o que, por sua vez, restringe a confiabilidade dos dados interpolados (Chuvieco e Martin, 1994). Em decorrência disso e pelo fato das distintas fontes de dados, a resolução espacial dos dados foi limitada em $27,8 \mathrm{~km}$, superior a de $50 \mathrm{~km}$ utilizada pelo Joint Research Center (JRC) da Comunidade Europeia (SAI, 2008), mas inferior à resolução de $10 \mathrm{~km}$ utilizada pelo Wildland Fire Assessment System (WFAS) do Serviço Florestal dos Estados Unidos (USFS, 2012). Como os dados meteorológicos do INPE/ CPTEC foram disponibilizados numa escala temporal mensal e os dados do MERGE originalmente adquiridos em resolução diária, as análises foram realizadas somente numa resolução temporal mensal.

\subsection{Focos de calor}

Foram utilizados dados de focos de calor, como indicadores de ocorrência de fogo, detectados pelo sensor Moderate Resolution Imaging Spectroradiometer (MODIS) a bordo do satélite AQUA da National Aeronautics and Space Administration (NASA), dos meses de julho, agosto, setembro e outubro dos anos de 2004 e 2005, disponibilizados pelo INPE. 
O sistema do INPE detecta a existência de fogo na vegetação sem ter condições de avaliar, de forma precisa, o tamanho da área que está queimando, com erros associados maiores que $20 \%$ (Setzer et al., 2007), ou o tipo de vegetação afetada. Fogo rasteiro no chão da floresta densa, nuvens cobrindo a região e imprecisão na localização do foco de queima, que no melhor caso é de $1 \mathrm{~km}$, mas pode chegar a $6 \mathrm{~km}$, são condições que limitam a confiabilidade de detecção de fogo, principalmente em floresta. Trabalhos de validação indicam que cerca de $80 \%$ dos focos estão em um raio de $1 \mathrm{~km}$ das coordenadas indicadas (INPE, 2013).

Não é possível inferir com precisão um número de focos de calor para os distintos tipos de cobertura vegetal e uso da terra no Amazonas. Apesar da real impossibilidade para determinar com exatidão a origem do foco de calor, acredita-se que a maior parte ocorre em áreas abertas para atividade agrícola. Assim, é bastante provável que a grande maioria dos focos de calor detectados na área de estudo ocorra em áreas desmatadas em anos anteriores, onde o fogo é utilizado no manejo de pastagens, cultivos agrícolas e vegetação secundária, apesar de ser possível observar feições de queimadas em áreas recém-desmatadas e cicatrizes de incêndios em áreas de florestas afetadas pelo fogo em 2005 (Vasconcelos et al., 2013a), que podem estar associadas aos focos de calor.

\subsection{Processamento dos dados meteorológicos e focos de calor}

Os dados meteorológicos foram primeiramente pré-processados no Grid Analysis and Display System (GrADS). Todo o processamento dos dados de focos de calor e meteorológicos foi realizado no sistema de informação geográfica (SIG) ArcGis.

Inicialmente, foi verificada a consistência dos dados meteorológicos com a exclusão dos valores ilegítimos, limitando os valores mensais da umidade relativa do ar de $0 \%$ a $100 \%$, da temperatura de $0{ }^{\circ} \mathrm{C}$ a $60{ }^{\circ} \mathrm{C}$ e da precipitação de $0 \mathrm{~mm}$ a 500 $\mathrm{mm}$. Os dados foram dispostos em uma grade numérica, numa escala temporal mensal para cada parâmetro meteorológico com resolução espacial de $0,25^{\circ}$. Cada ponto da grade regular teve um valor associado para cada um dos parâmetros meteorológicos, representando, dessa forma, a condição mensal em uma célula de $0,25^{\circ}$.

Depois de incorporados ao SIG foram selecionados os dados mensais de focos de calor detectados pelos satélites na área de estudo. Este procedimento resultou em arquivos contendo o número de focos detectados em cada mês (julho, agosto, setembro e outubro) durante o período de maior atividade de fogo no Amazonas em 2004 e 2005. Em seguida, foi realizada a intersecção de cada pixel apresentando focos de calor com cada parâmetro meteorológico do mesmo mês (Figura 1). O próximo passo foi extrair as células com informações de focos de calor resultando em dois conjuntos de células: com presença e ausência de focos de calor, para cada parâmetro meteorológico.

\subsection{Análise dos dados}

As condições meteorológicas mensais mínimas propícias à ocorrência de fogo e atendidas simultaneamente em todas as células no período de julho a outubro nos anos de 2004 e 2005 foram estabelecidas de acordo com a literatura, sendo limitadas em: precipitação acumulada mensal inferior a $100 \mathrm{~mm}$, temperatura média do ar superior a $24{ }^{\circ} \mathrm{C}$, e umidade relativa do ar inferior a $65 \%$. As condições meteorológicas das células com presença e ausência de focos e o número mensal de focos em cada célula foram determinados por meio da estatística descritiva dos dados.

Para verificar a existência de segregação dos parâmetros meteorológicos entre as células com e sem focos de calor nos dois anos foi aplicada a Análise de Componentes Principais (ACP). Depois de realizada a ordenação, os dados foram diferenciados em células com e sem focos de calor e entre os dois anos.

Para averiguar se os parâmetros meteorológicos apresentam valores preditivos para projetar a ocorrência do número de eventos de fogo foi aplicada uma regressão de Poisson, onde o número de focos foi a variável dependente e a precipitação, a temperatura máxima do ar e a umidade relativa do ar foram as variáveis independentes $(\mathrm{n}=8$; considerando os meses de julho, agosto, setembro e outubro de 2004 e 2005).

\section{RESULTADOS E DISCUSSÃO}

\subsection{Condições meteorológicas nas células com e sem focos de calor}

Durante a seca de 2004, 39\% das células $\left(116.000 \mathrm{~km}^{2}\right)$ apresentavam as condições meteorológicas mínimas propícias à ocorrência de fogo com um pico de $86 \%$ no mês de agosto (Tabela 1). Em 2005, mais de $72 \%$ das células $\left(213.000 \mathrm{~km}^{2}\right)$ apresentavam condições meteorológicas propícias à ocorrência de fogo, com picos de $97 \%$ em julho, $99 \%$ em agosto e $83 \%$ em setembro, com marcantes reduções no mês de outubro, nos dois anos $(3 \%$ e $9 \%)$.

Das 336 células identificadas com focos de calor em 2004, 161 (48\%) apresentaram as condições meteorológicas mínimas propícias ao fogo. Já em 2005, foram identificadas 443 células com focos de calor, das quais 349 (79\%) atenderam simultaneamente tais condições (Tabela 2), evidenciando um aumento de $117 \%$ em relação a 2004 . 
Tabela 1 - Número de células que atenderam simultaneamente as condições meteorológicas mínimas propícias à ocorrência de fogo* no período de julho a outubro nos anos de 2004 e 2005, no sul do Amazonas.

\begin{tabular}{|c|c|c|c|c|c|}
\hline \multirow[t]{2}{*}{ Mês } & \multirow[t]{2}{*}{ Total de Células } & \multicolumn{4}{|l|}{ Ano } \\
\hline & & 2004 & $\%$ & 2005 & $\%$ \\
\hline Julho & 513 & 321 & 63 & 499 & 97 \\
\hline Agosto & 513 & 440 & 86 & 506 & 99 \\
\hline Setembro & 513 & 30 & 6 & 425 & 83 \\
\hline Outubro & 513 & 14 & 3 & 46 & 9 \\
\hline Média (Julho a Outubro) & 513 & 201 & 39 & 369 & 72 \\
\hline
\end{tabular}

Tabela 2 - Número de focos de calor (satélite AQUA), número de células com focos de calor e número de células que atenderam simultaneamente as condições meteorológicas mínimas propícias à ocorrência de fogo* no período de julho a outubro nos anos de 2004 e 2005, no sul do Amazonas.

\begin{tabular}{|c|c|c|c|c|c|c|c|c|}
\hline \multirow[t]{2}{*}{ Mês } & \multicolumn{4}{|l|}{2004} & \multicolumn{4}{|l|}{2005} \\
\hline & $\begin{array}{l}\begin{array}{l}\mathbf{0} \\
\text { focos }\end{array}\end{array}$ & $\begin{array}{l}\text { Células } \\
\text { com } \\
\text { focos }\end{array}$ & $\begin{array}{l}\text { Células } \\
\text { propícias } \\
\text { ao fogo }\end{array}$ & $\%$ & $\begin{array}{l}\begin{array}{l}\text { № } \\
\text { focos }\end{array}\end{array}$ & $\begin{array}{l}\text { Células } \\
\text { com } \\
\text { focos }\end{array}$ & $\begin{array}{l}\text { Células } \\
\text { propícias } \\
\text { ao fogo }\end{array}$ & $\%$ \\
\hline Julho & 156 & 41 & 38 & 93 & 601 & 76 & 74 & 97 \\
\hline Agosto & 1.097 & 111 & 99 & 89 & 1.905 & 127 & 126 & 99 \\
\hline Setembro & 755 & 104 & 12 & 12 & 2.341 & 157 & 140 & 89 \\
\hline Outubro & 336 & 80 & 12 & 15 & 325 & 83 & 9 & 11 \\
\hline Julho a Outubro & 2.344 & 336 & 161 & 48 & 5.172 & 443 & 349 & 79 \\
\hline
\end{tabular}

*Condições meteorológicas mínimas propícias à ocorrência de fogo: precipitação acumulada mensal inferior a $100 \mathrm{~mm}$, temperatura média do ar superior a $24^{\circ} \mathrm{C}$, e umidade relativa do ar inferior a $65 \%$.

No geral, o número mensal de células com focos que atenderam simultaneamente as condições meteorológicas propícias à ocorrência de fogo foi maior em agosto, em $2004 \mathrm{e}$ em agosto e setembro, em 2005.

As condições meteorológicas, nas quais ocorreu maior incidência de fogo, são próximas àquelas apresentadas em outros estudos conduzidos na Amazônia por meio de medidas micrometeorológicas e em escala local (p. ex. Uhl e Kauffman, 1990; Nepstad et al., 1994; Mendoza, 2003; Ray et al., 2005). No ano de seca normal, menos da metade da área do sul do Amazonas estava suscetível ao fogo. Porém, no ano de seca severa a área sucetível ao fogo foi substancialmente maior, correspondendo a um aumento de $84 \%$, comparado ao ano sob condição de seca normal. O número de células com focos em 2005 foi $66 \%$ maior que em 2004, evidenciando a forte influência que os componentes climáticos exercem sobre a suscetibilidade da vegetação ao fogo, o que pode ter intensificado o uso do fogo pela atividade humana nessa região em 2005 (Vasconcelos et al., 2013b).

Nos últimos 20 anos, na Amazônia brasileira, extensas áreas de floresta e não floresta (com cultivos agrícolas, pasto e vegetação secundária) foram queimadas acidentalmente durante eventos extremos de seca potencializados pelo El Niño em 1997/1998 (Barbosa e Fearnside, 1999; Alencar et al., 2006) e, mais recentemente, pelo aquecimento anômalo das temperaturas de superfície do oceano Atlântico Norte tropical (Brown et al., 2006; Shimabukuro et al., 2009; Vasconcelos et al., 2013a). As condições meteorológicas atípicas, existentes durante esses eventos de seca extrema, contribuem para a intensificação do uso do fogo por humanos, que pode sair do controle e levar a um aumento substancial de focos de calor (Alencar et al., 2006; Vasconcelos et al., 2013b).

Considerando os parâmetros meteorológicos, os valores médios da precipitação apresentaram maior amplitude de 
variação entre os meses e anos, nos dois conjuntos de células, quando comparado com os demais (Tabela 3). As médias mensais da temperatura máxima foram similares nos dois conjuntos de células, mas maiores $\left(1{ }^{\circ} \mathrm{C}\right.$ em média) durante os meses mais quentes (agosto e setembro) e com maior amplitude de variação em 2005. O aumento na temperatura do ar influencia diretamente a evapotranspiração, contribuindo para um estresse hídrico mais rápido e, consequentemente, para maior flamabilidade da vegetação ao fogo (Nepstad et al., 2004). Costa e Foley (2000) alertaram que um aumento da temperatura associado com o aquecimento global pode exacerbar os efeitos da seca, acelerando o processo de evaporação.

As temperaturas mínimas mensais, em sua maioria, também foram análogas nos dois conjuntos de células. Entretanto, as mínimas registradas entre julho e setembro de 2005 foram mais baixas que em 2004, o que pode ser explicado pelas ondas de frios comumente observadas na região (fenômeno da friagem) nessa época do ano. Em sua maioria, os valores médios da umidade relativa do ar foram menores nos conjuntos de células com focos, mas similares entre os anos. No geral, as médias dos parâmetros foram próximas entre si.

\subsection{Focos de calor em relação às condições meteorológicas}

O número de focos de calor detectado nos meses de julho a outubro de 2004 foi de 2.344 (Tabela 2). Destes, 78\% (1.819) ocorreram em células com precipitação mensal inferior a 100 $\mathrm{mm}$, com maior incidência (65\%) em células com precipitação entre $40 \mathrm{~mm}$ e $90 \mathrm{~mm}$. Nos meses de agosto e setembro ocorreram $90 \%$ dos focos de calor (Figura 2).
Em 2005, foram detectados 5.172 (Tabela 2), sendo que cerca de $90 \%$ ocorreram em células com precipitação mensal inferior a $100 \mathrm{~mm}$, com $83 \%$ dos focos ocorrendo em células com precipitação inferior a $70 \mathrm{~mm}$, sobretudo entre julho e setembro.

Em de 2004, mais de 96\% dos focos de calor ocorreram com temperatura máxima entre $32{ }^{\circ} \mathrm{C}$ e $33{ }^{\circ} \mathrm{C}$, temperatura mínima entre $19{ }^{\circ} \mathrm{C}$ e $22{ }^{\circ} \mathrm{C}$, e temperatura média entre $26^{\circ} \mathrm{C}$ e $28^{\circ} \mathrm{C}$. Considerando o ano de 2005 , mais de $96 \%$ dos focos detectados ocorreram com temperatura máxima entre $31^{\circ} \mathrm{C}$ e $34^{\circ} \mathrm{C}$, temperatura mínima entre $17^{\circ} \mathrm{C}$ e $22^{\circ} \mathrm{C}$, e temperatura média entre $24{ }^{\circ} \mathrm{C}$ e $28{ }^{\circ} \mathrm{C}$. A amplitude de variação das temperaturas máxima e mínima foi maior em 2005. Em 2004, $89 \%$ (2.094) dos focos ocorreram com umidade relativa do ar inferior a 65\%. Já em 2005, o percentual foi de 99\% (5.161).

A ocorrência de focos de calor em áreas com precipitação acumulada mensal superior a $100 \mathrm{~mm}$ e com umidade relativa do ar superior a $65 \%$ pode ser explicada pela baixa resolução espacial e temporal dos dados meteorológicos, com a decisão humana de atear fogo na vegetação e com o período de estiagem.

O clima exerce um forte controle sobre incêndios e queimadas repetidas na região Amazônica (Morton et al., 2013). Alencar et al. (2011) mostraram estreita relação entre a área queimada anualmente e indicadores climáticos de seca local, demonstrando distribuição triangular, na qual há maior variação de área queimada, ocorrendo durante os anos com menor quantidade de precipitação e estação seca prolongada.

Mesmo com a tendência de separação nos valores dos parâmetros meteorológicas entre os anos de 2004 e 2005 (Figura 3A), foi observada forte similaridade nos valores dos parâmetros entre as áreas com e sem focos de calor (Figura 3B). Entretanto, em 2005 houve um aumento da área suscetível

Tabela 3 - Médias das condições meteorológicas mensais nos anos de 2004 e 2005 nas células com e sem focos de calor, no sul do Amazonas.

\begin{tabular}{|c|c|c|c|c|c|c|c|c|c|c|}
\hline \multirow[t]{2}{*}{ Mês } & \multicolumn{2}{|c|}{$\begin{array}{l}\text { Precipitação } \\
(\mathrm{mm})\end{array}$} & \multicolumn{2}{|c|}{$\begin{array}{l}\text { Temperatura } \\
\text { Mínima }\left({ }^{\circ} \mathbf{C}\right)\end{array}$} & \multicolumn{2}{|c|}{$\begin{array}{l}\text { Temperatura } \\
\text { Média }\left({ }^{\circ} \mathbf{C}\right)\end{array}$} & \multicolumn{2}{|c|}{$\begin{array}{l}\text { Temperatura } \\
\text { Máxima }\left({ }^{\circ} \mathbf{C}\right)\end{array}$} & \multicolumn{2}{|c|}{$\begin{array}{l}\text { Umidade } \\
\text { Relativa }(\%)\end{array}$} \\
\hline & 2004 & 2005 & 2004 & 2005 & 2004 & 2005 & 2004 & 2005 & 2004 & 2005 \\
\hline \multicolumn{11}{|c|}{ Células com focos de calor } \\
\hline Julho & 55 & 18 & 21 & 19 & 26 & 26 & 32 & 32 & 52 & 53 \\
\hline Agosto & 64 & 34 & 21 & 20 & 27 & 27 & 33 & 34 & 50 & 50 \\
\hline Setembro & 177 & 55 & 22 & 21 & 27 & 27 & 33 & 34 & 51 & 51 \\
\hline Outubro & 169 & 147 & 23 & 23 & 28 & 28 & 33 & 34 & 62 & 62 \\
\hline \multicolumn{11}{|c|}{ Células sem focos de calor } \\
\hline Julho & 67 & 20 & 21 & 20 & 26 & 26 & 32 & 33 & 54 & 54 \\
\hline Agosto & 77 & 33 & 21 & 20 & 27 & 27 & 33 & 34 & 51 & 51 \\
\hline Setembro & 184 & 72 & 22 & 21 & 28 & 28 & 33 & 34 & 52 & 52 \\
\hline Outubro & 185 & 164 & 23 & 23 & 28 & 28 & 33 & 34 & 61 & 61 \\
\hline
\end{tabular}


e maior persistência das condições meteorológicas propícias ao fogo, mas tais condições não apresentaram segregação, indicando homogeneidade entre as áreas com e sem focos de calor. Os dois eixos juntos explicaram $84 \%$ da variação dos dados $(\mathrm{PC} 1=54 \%, \mathrm{PC} 2=30 \%)$.

$\mathrm{O}$ modelo geral de regressão de Poisson apresentou forte correlação entre os dados observados utilizando todos os parâmetros, com valores preditivos para ocorrência de focos, com coeficientes significativos $(\mathrm{b}=0,83 ; p<0,001 ; \mathrm{EP}=0,13 ; \mathrm{n}$ $=8)$ (Figura 4D). Forte correlação inversa foi observada entre as variáveis focos de calor e precipitação $(\mathrm{b}=-0,002 ; p<0,001$; EP $=0,0003 ; \mathrm{n}=8)($ Figura $4 \mathrm{~A}) \mathrm{e}$ focos de calor e umidade relativa do ar $(b=-0,148 ; p<0,001 ; E P=0,0005 ; n=8)$ (Figura 4C), e forte correlação positiva entre focos de calor e temperatura máxima do ar $(\mathrm{b}=0,78 ; p<0,001 ; \mathrm{EP}=0,02 ; \mathrm{n}=8)$ (Figura 4B). Quanto maior a temperatura do ar e menor a precipitação e umidade, maior será a probabilidade de ocorrência de focos
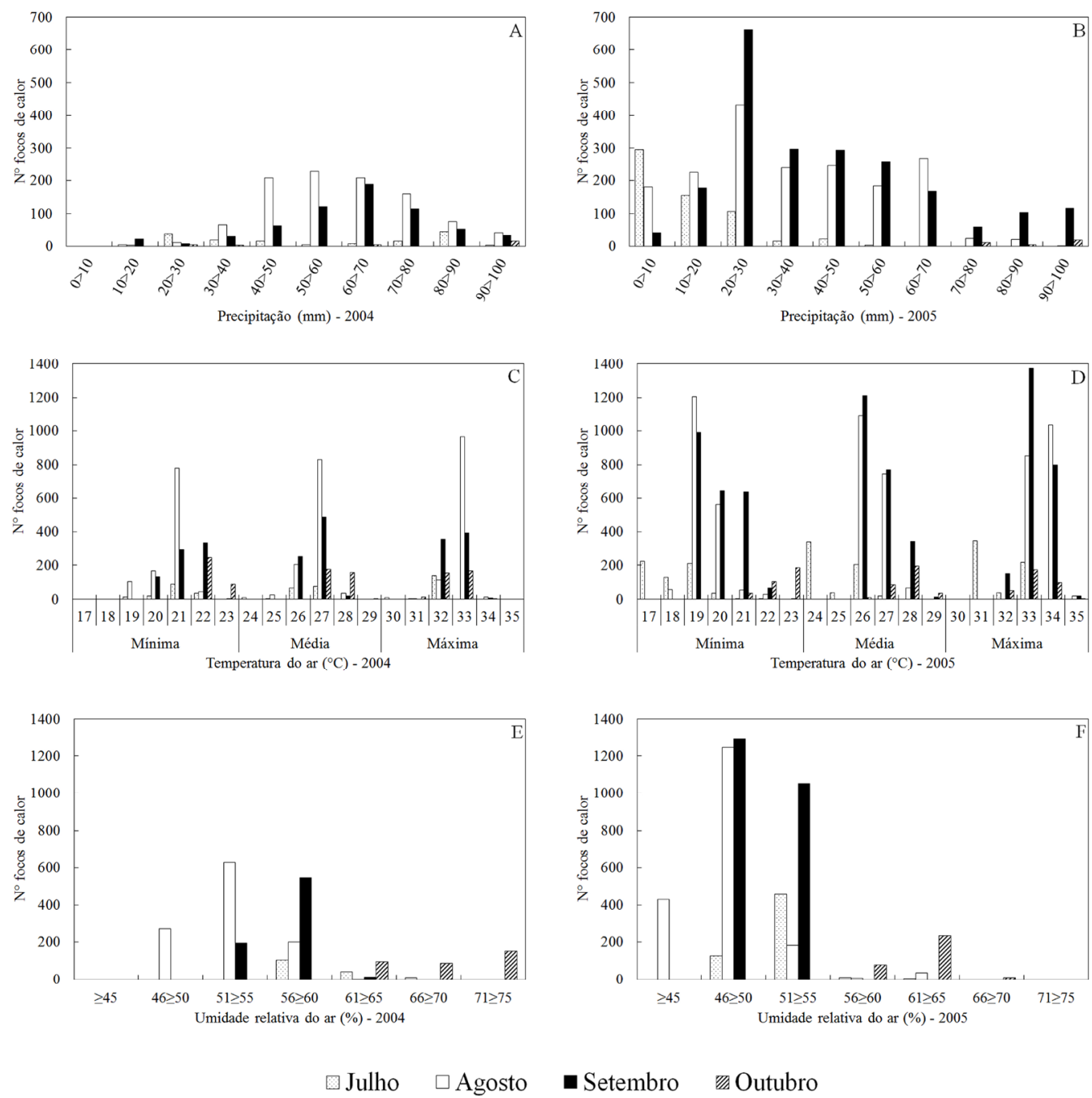

Figura 2 - Distribuição mensal do número de focos de calor em relação à precipitação $(\mathrm{mm})$, temperaturas do ar mínima, média e máxima $\left({ }^{\circ} \mathrm{C}\right)$, e umidade relativa do ar (\%) no sul do Amazonas nos anos de 2004 (A, C e E) e 2005 (B, D e F). de calor. Considerando os outros parâmetros, os modelos apresentaram respostas semelhantes.

A umidade relativa do ar influencia o conteúdo de umidade do combustível, e quanto menor a umidade relativa do ar, maior é a intensidade do fogo (Trollope et al., 2004). A maioria dos grandes incêndios ocorre com a umidade do combustível extremamente baixa, causada por condições de seca severa ou prolongada, que combinadas com altas temperaturas e baixa umidade relativa do ar e, muitas vezes, com fortes ventos, favorecem o espalhamento (Colson, 2004) e a propagação do fogo (Silvestrini et al., 2011).

A diminuição da precipitação, da umidade relativa do ar e elevadas temperaturas confirmam estreita correlação com a ocorrência de fogo e com a flamabilidade do combustível. Em Samarinda, na costa leste de Kalimantan, Indonésia, cerca de $3,5 \times 10^{6}$ ha foram afetados pelo fogo durante a seca de grande magnitude e persistência decorrente do El Niño de 1982/1983, 
quando a precipitação chegou a 35\% abaixo da média anual, com nível crítico inferior a $100 \mathrm{~mm} / \mathrm{mês}$ durante 10 meses (Goldammer e Seibert, 1990).

A temperatura do ar afeta consideravelmente as mudanças de umidade no combustível vegetal, pois elevadas temperaturas do ar ajudam a secar mais rapidamente o combustível, consequentemente, tornando-o mais inflamável (Ronde et al., 1990). Fogos experimentais conduzidos no leste da bacia Amazônica mostram que o fogo pode ocorrer com temperatura do ar na floresta secundária acima de 32 ${ }^{\circ} \mathrm{C}$, na floresta explorada e/ou queimada acima de $29{ }^{\circ} \mathrm{C}$, na floresta intacta acima de $28^{\circ} \mathrm{C}$, e em áreas abertas acima de
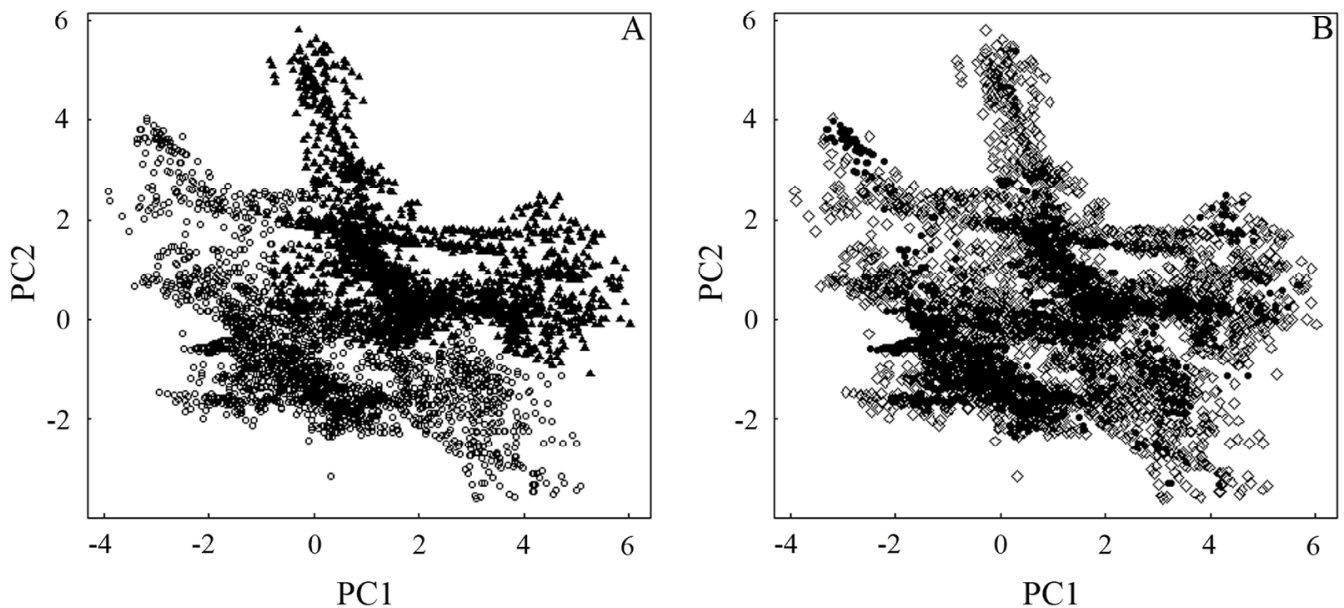

Figura 3 - Análise de componentes principais (PCA) dos parâmetros meteorológicos entre os anos de 2004 e 2005 (A - onde triângulos pretos são as células de 2004 e círculos são as células de 2005) e entre os conjuntos de células com e sem focos de calor (B - onde os círculos pretos são as células com focos de calor e os diamantes são as células sem focos de calor).
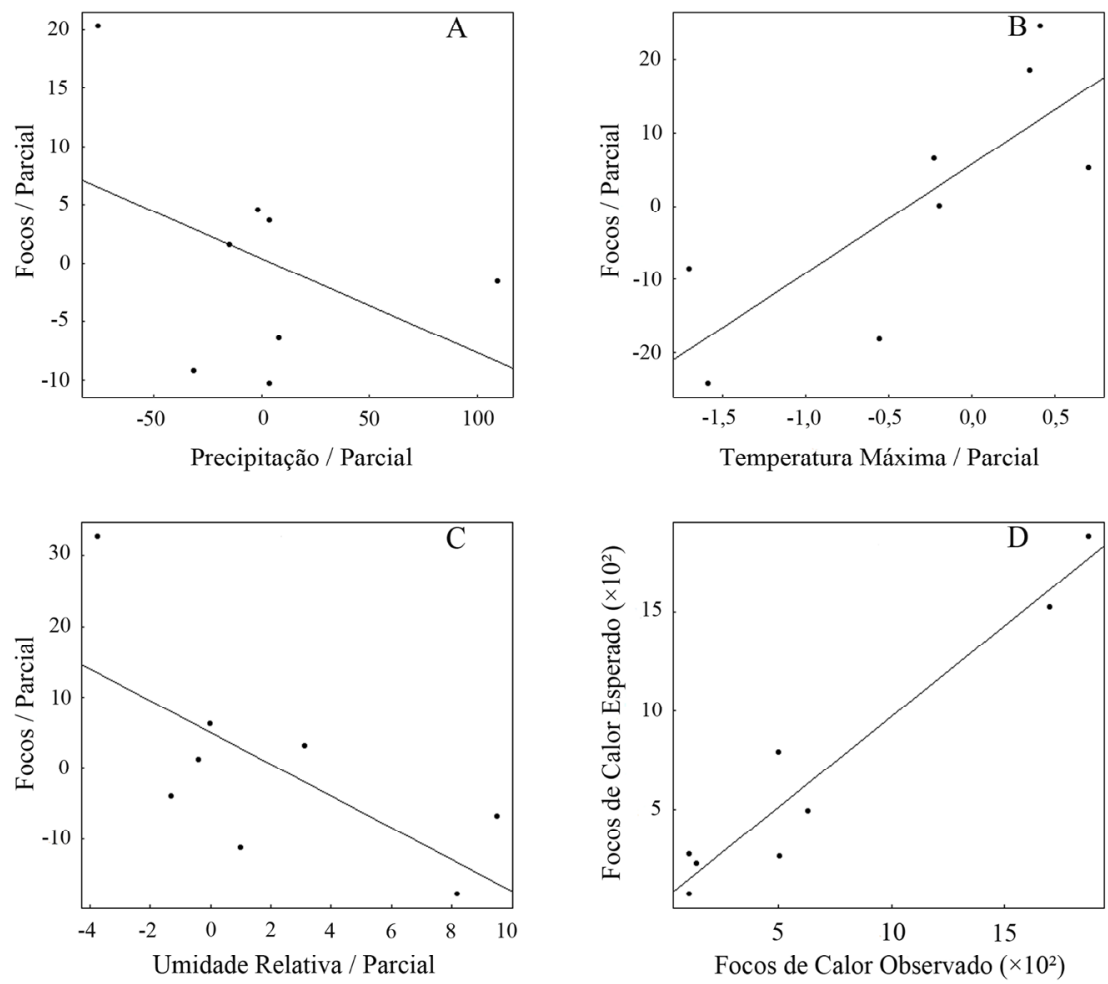

Figura 4 - Modelo geral do número de focos de calor observados contra o número de focos de calor esperados pelo modelo regressão de Poisson (D - Número de focos de calor $\left.=e^{(-11,45-0,002 * \text { precipitação }+0,78 * \text { Temperatura máxima - 0,148*Umidade relativa) }}\right)$ dos anos de 2004 e 2005 . Descrição dos modelos das parciais contra o número de focos de calor, $\mathrm{A}, \mathrm{B}$ e $\mathrm{C}$. 
$24{ }^{\circ} \mathrm{C}$ (Ray et al., 2005). Temperatura do ar acima de $29{ }^{\circ} \mathrm{C}$ proporcionam condições favoráveis à propagação de fogo na floresta (Mendoza, 2003).

Durante esses anos atípicos de seca prolongada com variações climáticas extremas, se a floresta não armazenar água suficiente durante o período de chuva, sofrerá um estresse hídrico acima do normal, que com baixo estoque de água no solo influenciará diretamente a evapotranspiração (Gatti et al., 2014). Além disso, a disponibilidade de água no solo para as plantas é um fator que limita a produtividade vegetal na floresta Amazônica (Morton et al., 2014). A combinação de todos esses fatores somados à decisão humana de atear fogo na vegetação, principalmente próximo às bordas das florestas, pode ter favorecido a ocorrência de incêndios florestais durante a grande seca de 2005, quando mais de $865 \mathrm{~km}^{2}$ localizados nos municípios de Boca do Acre e Lábrea, porção oeste da área de estudo (Vasconcelos et al., 2013a) e mais de $3.600 \mathrm{~km}^{2}$ no leste do Acre (Brown et al., 2006) foram afetados pelo fogo acidentalmente.

\subsection{Implicações para políticas públicas}

Nossos resultados mostram que secas de grande magnitude e persistência proporcionam condições de tempo quente e seco favorável ao fogo, que atrelado à decisão humana de atear fogo na vegetação, podem exacerbar a ocorrência de queimadas e incêndios florestais na região. Informações sobre a suscetibilidade da vegetação ao fogo, com base nas condições meteorológicas, podem ser utilizadas no manejo e preservação do bioma Amazônico para fins de conservação, tendo em vista que os parâmetros meteorológicos são fortemente preditivos para projetar a ocorrência de fogo na vegetação.

O conhecimento e compreensão das condições meteorológicas e suas interações com a suscetibilidade da vegetação ao fogo podem ser úteis para o desenvolvimento de políticas de gestão mais adequadas dos recursos ambientais para essa região, pois são essenciais para maximinar o monitoramento, a prevenção, o combate e o controle eficiente das queimadas e incêndios em áreas urbanas e rurais. Alertas poderiam ser emitidos para as áreas onde o risco de incêndio for maior, incluindo àquelas destinadas à preservação e seu entorno. Por outro lado, seriam localizadas as áreas de menor suscetibilidade, onde o uso do fogo de forma controlada poderia ser permitido para queimadas, tendo em vista a importância que o fogo exerce no paradigma de desenvolvimento da Amazônia.

Essas informações são relevantes na concessão de licença para queima e no planejamento de medidas preventivas a incêndios (como aceiros) viabilizando melhor alocação de recursos por ter uma relação custo/benefício favorável, em comparação com as medidas supressivas (Soares, 1985), principalmente em regiões remotas e de difícil acesso, como a Amazônia. Além disso, são úteis para modelagem de risco de fogo (Nepstad et al., 1999; Nepstad et al., 2004), de espalhamento (Ray et al., 2005), e de regime do fogo na Amazônia (Silvestrini et al., 2011; Soares-Filho et al., 2012).

\section{CONCLUSÕES}

No ano sem seca severa, o maior percentual de focos de calor ocorreu em células com baixa precipitação mensal entre $40 \mathrm{~mm}$ e $90 \mathrm{~mm}(65 \%)$, temperatura mínima entre 19 e $22^{\circ} \mathrm{C}$, temperatura média entre 26 e $28^{\circ} \mathrm{C}$, temperatura máxima entre 32 e $33{ }^{\circ} \mathrm{C}(96 \%)$ e com umidade relativa inferior a $65 \%(89 \%)$.

Em 2005, ano com seca severa, o número de células suscetíveis ao fogo e o número de focos de calor foram substancialmente maiores que em 2004. O maior percentual de focos ocorreu em células com precipitação mensal inferior a 70 $\mathrm{mm}(83 \%)$, temperatura mínima entre 17 e $22^{\circ} \mathrm{C}$, temperatura média entre 24 e $28{ }^{\circ} \mathrm{C}$, temperatura máxima entre 31 e $34{ }^{\circ} \mathrm{C}$ (96\%) e com umidade relativa inferior a 65\% (99\%).

Essas condições de tempo mais quente e mais seco no ano de seca severa, por período prolongado, proporcionam um aumento da área com condições meteorológicas propícias ao fogo e potencializam a suscetibilidade da vegetação a queimadas e incêndios florestais nessa região.

\section{AGRADECIMENTOS}

Os autores agradecem ao Conselho Nacional de Desenvolvimento Científico e Tecnológico (CNPq, 563315/20083) e ao Programa Nacional de Pós Doutorado da Coordenação de Aperfeiçoamento de Pessoal de Nível Superior (PNPD/CAPES) (projeto: 028176/2009-41) pelas bolsas concedidas; ao Instituto Nacional de Ciência e Tecnologia de Serviços Ambientais da Amazônia (INCTServamb) do Instituto Nacional de Pesquisas da Amazônia (INPA) pelo suporte financeiro (projetos: 305880/2007-1, 143399/0, 575853/2008-5, 2008-7/573810), e ao Instituto Nacional de Pesquisas Espaciais (INPE) por disponibilizar os dados de focos de calor e meteorológicos.

\section{REFERÊNCIAS BIBLIOGRÁFICAS}

ALENCAR, A. C.; NEPSTAD, D.; DIAZ, M. C.V. Forest understory fire in the Brazilian Amazon in ENSO and nonENSO years: area burned and committed carbon emissions.

Earth Interactions, v. 10, n. 6, p. 1-17, 2006.

ALENCAR, A. et al. Temporal variability of forest fires in eastern Amazonia. Ecological Applications, v. 21, n. 7, p. 2397-2412, 2011. 
ALVARES, C. A. et al. Köppen's climate classification map for Brazil. Meteorologische Zeitschrift, v. 22, n. 6, p. 711-728, 2013.

ASNER, G. P.; ALENCAR, A. Drought impacts on the Amazon forest: the remote sensing perspective. New Phytologist, v. 187, p. 569-578, doi: 10.1111/j.1469-8137.2010.03310.x, 2010.

BARBOSA, R. I.; FEARNSIDE, P. M. Incêndios na Amazônia brasileira: estimativa da emissão de gases do efeito estufa pela queima de diferentes ecossistemas de Roraima na passagem do Evento El Niño (1997/98). Acta Amazonica, v. 29, n. 4, p. 513-534, 1999.

BRANDO, P. M. et al. Abrupt increases in Amazonian tree mortality due to drought-fire interactions. Proceedings of the National Academy of Sciences of the United States of America, v. 107, n. 33, p. 1-6, doi:10.1073/ pnas.1305499111, 2014.

BROWN, I. F. et al. Monitoring fires in Southwestern Amazonia rain forest. EOS, Transactions of the American Geophysical Union, v. 87, n. 26, p. 253-264. 2006.

CARDOSO, M. F. et al. Projecting future fire activity in Amazonia. Global Change Biology, v. 9, p. 656-669, 2003.

CARVALHO JR., J. A.; LACAVA, P. T. Emissões em processo de combustão. São Paulo: UNESP, 2003, 135 p.

CHUVIECO, E.; MARTIN, M. P. Global fire mapping and fire danger estimation using AVHRR images. Photogrammetric Engineering and Remote Sensing, v. 60, n. 5, p. 563-570, 1994.

ChUVieco, E.; Giglio, L.; JUstiCe, C. Global characterization of fire activity: toward defining fire regimes from Earth observation data. Global Change Biology, v. 14. p. 1488-1502, doi: 10.1111/j.1365-2486.2008.01585.x, 2008.

COCHRANE, M. A. Fire science for rainforests. Nature, v. 421, p. 913-919, 2003.

COLSON, D. Meteorological problems associated with mass fires. Fire Management Today, v. 64, n. 1, p. 34-36. 2004.

COSTA, M. H.; FOLEY, J. A. Combined effects of deforestation and doubled atmospheric $\mathrm{CO}_{2}$ concentrations on the climate of Amazonia. Journal of Climate, v. 13, p. 18-34, 2000.

FEARNSIDE, P. M. Fire in the tropical rain Forest of the Amazon basin. In: GOLDAMMER, J. G. (Ed.). Fire in the Tropical Biota. Berlim: Spring-Verlag, 1990. p. 106-116.

GATTI, L. V. et al. Drought sensitivity of Amazonian carbon balance revealed by atmospheric measurements. Nature, v. 506, p. 76-80, doi:10.1038/nature12957, 2014.

GOLDAMMER, J. G.; SEIBERT, B. The impact of droughts and forest fires on tropical lowland rain forest of East Kalimantan. In: GOLDAMMER, J. G. (Ed.). Fire in the Tropical Biota. Berlim: Spring-Verlag, 1990, p. 11-31.
IBGE. Instituto Brasileiro de Geografia e Estatística. Mapa de Clima do Brasil. Rio de Janeiro, 2002. Disponível em: $<$ mapas.ibge.gov.br/clima/viewer.htm>, Acesso em 18 ago. 2012.

IBGE. Instituto Brasileiro de Geografia e Estatística. Manual Técnico da Vegetação da Brasileira. Rio de Janeiro, 2004. Disponível em: <mapas.ibge.gov.br/vegetação/viewer.htm>. Acesso em 18 ago. 2012.

IBGE. Instituto Brasileiro de Geografia e Estatística. Estados. Brasília, 2012. Disponível em: <http://www.ibge.gov.br/ estadosat/perfil.php?sigla=am>. Acesso em 12 set. 2012.

INPE. Instituto Nacional de Pesquisas Espaciais. Monitoramento de Queimadas, São José dos Campos, 2013. Disponível em: $<$ http://www.inpe.br/bdqueimadas/feq.php $>$. Acesso em 17 jan. 2013.

INPE. Instituto Nacional de Pesquisas Espaciais. Projeto Prodes - Monitoramento da Floresta Amazônica Brasileira por Satélite, São José dos Campos, 2014. Disponível em: $<$ http://www.dpi.inpe.br/prodesdigital/prodesmunicipal. php>. Acesso em 25 abr. 2014

MENDOZA, E. R. H. Susceptibilidade da floresta primária ao fogo em 1998 e 1999: estudo de caso no Acre, Amazônia sul-ocidental, Brasil. 40 p. Dissertação (Mestrado em Ecologia e Manejo de Recursos Naturais). Universidade Federal do Acre, Rio Branco, 2003.

MORTON, D. C. et al. Agricultural intensification increases deforestation fire activity in Amazonia. Global Change Biology, v. 14, p. 2262-2275, doi: 10.1111/j.13652486.2008.01652.x, 2008.

MORTON, D. C. et al. Understorey fire frequency and the fate of burned forests in southern Amazonia. Philosophical Transactions of the Royal Society B, v. 368, p. 20120163 , doi: 10.1098/rstb.2012.0163, 2013.

MORTON, D. C. et al. Amazon forests maintain consistent canopy structure and greenness during the dry season. Nature, v. 506, p. 221-224, doi:10.1038/nature13006, 2014.

NEPSTAD, D. C.; MOREIRA, A. G.; ALENCAR, A. A. A floresta em chamas: Origens, impactos e prevenção de fogo na Amazônia. Brasília: Brazil Pilot Program to Conserve the Brazilian Rain Forest, 1999. 202 p.

NEPSTAD, D. C. et al. The role of deep roots in the hydrological and carbon cycles of Amazonian forests and pastures. Nature, v. 372, p. 666-669, 1994.

NEPSTAD, D. C. et al. Amazon drought and its implications for forest flammability and tree growth: a basin-wide analysis. Global Change Biology, v. 10, p. 704-717, doi: 10.1111/j.1529-8817.2003.00772.x., 2004.

NEPSTAD, D. C. et al. Mortality of large trees and lianas following experimental drought in an Amazon forest. Ecology, v. 88, n. 9, p. 2259-2269, 2007. 
PEREIRA JR., A. C. Métodos de geoprocessamento na avaliação da suscetibilidade do Cerrado ao fogo. 97 p. Tese (Doutorado em Ecologia e Recursos Naturais). Universidade Federal de São Carlos, São Carlos, 2003.

RADAMBRASIL. Levantamento de Recursos Naturais. Ministério das Minas e Energia, Rio de Janeiro, 1983. V. 19-20.

RAY, D.; NEPSTAD, D.; MOUTINHO, P. Micrometeorological and canopy controls of fire susceptibility in a forested Amazon landscape. Ecological Applications, v. 15, n. 5 , p. 1664-1678, 2005.

RONDE, C. et al. Prescribed fire in industrial plantations. In: GOLDAMMER, J. G. (Ed.). Fire in the Tropical Biota. Berlim: Spring-Verlag, 1990, p. 216-272.

SAI, SPACE APPLICATION INSTITUTE. Assessment of forest fire risk in European Mediterranean region: comparison of satellite-derived and meteorological indices, 2008. Disponível em: <publications.jrc.ec.europa. eu/repository/bitstream>. Acesso em 21 set. 2012.

SETZER, A.; MORELLI, F.; RIVERA-LOMBARD, R. Estimativa quinzenal de áreas queimadas. In: RUDORFF, B. F. T.; SHIMABUKURO, Y. E.; CEBALlHOS, J. C. Sensor Modis e suas Aplicações Ambientas no Brasil. São José dos Campos: Parêntese, 2007. 448 p.

SHIMABUKURO, Y. E. et al. Fraction images derived from Terra Modis data for mapping burnt areas in Brazilian Amazonia. International Journal Remote Sensing, v. 30, n. 6, p. 1537-1546, 2009.

SILVESTRINI, R. A. et al. Simulating fire regimes in the Amazon in response to climate change and deforestation. Ecological Applications, v. 21, n. 5, p. 1573-1590, 2011.
SOARES, R.V. Incêndios florestais - controle e uso do fogo. Fundação de Pesquisas Florestais do Paraná, Curitiba: FUPEF, 1985, 213 p.

SOARES-FILHO, B. et al. Forest fragmentation, climate change and understory fire regimes on the Amazonian landscapes of the Xingu headwaters. Landscape Ecology, v. 27, p. 585598, doi: 10.1007/s10980-012-9723-6, 2012.

SOMBROEK, W. Spatial and temporal patterns of Amazon fainfall. Ambio, v. 30, n. 7, p. 388-396, 2001.

TROLlOPE, W. S. W.; DE RONDE, C.; GELDENHUYS, C. J. Fire Behaviour. In: GOLDAMMER, J. G.; RONDE, C. (Eds.). Wildland fire management handbook for SubSaharan Africa. Alemanha: Frieburg University, 2004, $432 \mathrm{p}$.

UHL, C.; KAUFFMAN, J. B. Deforestation, Fire Susceptibility, and Potential Tree Responses to Fire in the Eastern Amazon. Ecology, v. 71, p. 437-449, doi:10.2307/1940299, 1990.

USFS, UNITED STATES FOREST SERVICE. Wildland Fire Assessment System, 2012. Disponível em: <www.wfsa. net/index.php/fire-danger-rating-fire-potential--danger32? format $=$ pdf $>$. Acesso em 21 set. 2012.

VASCONCELOS, S. S. et al. Forest fires in southwestern Amazonia: Estimates of area and potential carbon emissions. Forest Ecology and Management, v. 291, p. 199-208. doi: 10.1016/j.foreco.2012.11.044, 2013a.

VASCONCELOS, S. S. et al. Variability of vegetation fires with rain and deforestation in Brazil's state of Amazonas. Remote Sensing of Environment, v. 136, p. 199-209, doi: 10.1016/j.rse.2013.05.005, 2013b. 